\title{
A Technological Innovation Management Based on the Audit
}

\author{
Ya Liao \\ Business School, University of Shanghai for Science and Technology \\ 516 Jun Gong Road, Shanghai 200093, China \\ E-mail: zhanguo2005@126.com \\ Yiyang Fan \\ Business School, University of Shanghai for Science and Technology \\ 516 Jun Gong Road, Shanghai 200093, China \\ E-mail: fyyqq@usst.edu.cn \\ Yi Xi \\ Business School, University of Shanghai for Science and Technology \\ 516 Jun Gong Road, Shanghai 200093, China \\ E-mail:cyfxy0498@126.com
}

Received: December 13, 2010 Accepted: January 13, 2011 doi:10.5539/ibr.v4n2p170

The research is financed by The Innovation Fund Project For Graduate Student of Shanghai (JWCXSL1002) and Innovation Program of Shanghai Municipal Education Commission(09ZS160).

\begin{abstract}
This paper analyzes the status of technological innovation management, made a complete concept of technological innovation audit, and sets up a conceptual model of technical innovation audit using systems engineering method. We puts forward an integrity concept of stakeholders at all levels, established a concept model of technological innovation audit and presents the workflow and common method of implementing technological innovation audit.
\end{abstract}

Keywords: Technological innovation audit, Technological innovation management, Stakeholders

\section{The concept of technological innovation management}

Since $90 \mathrm{~s}$ of $20^{\text {th }}$ century, global competition is mainly reflected in the strength of economic and technological competition, and technological innovation is increasingly becoming the promotion of economic development and the key of technological progress. More and more companies find that only with good quality, a sufficiently high efficiency, flexible organizational structure can not meet the requirements to remain competitive. They will pay more attention to the effective management of technological innovation.

Technological innovation management is for the allocation of resources in technological innovation process, including technical origin R \& D), technology (including designing, manufacturing, sales and service of commercial, industrial processes) and other processes. Technological innovation management has gone through the individual innovation management stage, organizational innovation management stage and comprehensive management stage. The late 20th century, technological innovation management has entered the era of comprehensive management.

\section{The concept of technical innovation audit}

Technological innovation audit is an important breakthrough in technological innovation management practices. Technical Innovation Audit Committee who base on certain procedures and methods and combine with audit and technical innovation, take technological innovation as the main audit object, identify problems and propose solutions to improve the quality of management in order to promote the performance's improvement.

As a dynamic flow of the loop, technical innovation audit include three stages, there are audit of the core business, the auxiliary system audit, security audit. 


\section{Technological innovation stakeholders}

The survival and development of enterprise is inseparable from all aspects of the relationship which can be summarized in several categories of stakeholders constituting the main users' groups of technological innovation audit. They include the government (providing innovation funds and the administrative supervision), banks (providing credit loans), VC (providing venture capital) and the owners. (Figure 1)

Innovation fund for technology based firms is a special government fund set up upon the approval of the State Council. In recent five years, there were 4676 projects subsidized which include 326 terminated projects. The project was unable to carry out accounts for $46 \%$, fell behind $20.9 \%$ seriously; the enterprise is unable to relate accounts for $15 \%$. Therefore, the country need the technological innovation audit display function to strengthen the technological innovation management and forms a good investment guidance system.

The bank through provide unsecured loan becomes enterprise's creditor. Whether take back the loan relates to the bank's stable and the sustainable development. Former loan origination judge by enterprise and bank cooperation, but the technological innovation enterprise has the high risk with high repayment. Finding the high quality property and the potential enterprise in many mortgage applications becomes one of banking industry's key goals.

$\mathrm{VC}$ pursues exceed profit, they are finding the potential enterprise, infused the fund to them and participate in their management and operation. How to find the best one is the problem. Technological innovation audit is one kind of quite feasible management tool.

The owner, including the shareholders and the investors in capital market, are company's creditors. They always lack of the experience to the management and need technological innovation report to tell them how the company operates, what is the investment rate and so on.

\section{Technological innovation audit model}

According to the auditing theory, the technological innovation audit model has included the audit stakeholders, the audit object, the audit team and the audit content and so on several factors. (Figure 2)

\subsection{Technological innovation audit's object and content}

Technological innovation audit's object includes the basic process and the auxiliary system. (Table 1)

Basic process is the core process of technological innovation audit, it is the scientific assessment. In this process, we analyze the differences between existing one and optimization one, give the audit report according to the enterprise's goal. We can help the enterprise find business process which matches the core goal, which need improvement, and help they understand who is able to provide methods and how to improve.

Auxiliary system is the audit function in the combination with management. Including surveillance, coordinated, control and so on managed capacity appraisals and resources supplies, strategic plan, environment and so on overall quality examination. Auxiliary system is composed of the following basic audit content: first, whether is enterprise resources possible arrangement? Second, whether the administrative management does achieve the modern management requirements? Third, whether the professionals have the enough knowledge? Whether the enterprise has the enough technical personnel?

\subsection{Technological innovation audit's team}

The technological innovation audit implements by the special independent auditors, involves the technical research and development, the examination, human resources management, the financial control, the market analysis, even includes the service movement, the production operation, the achievement transformation and so on various work, is high to the auditors' overall quality request.

Overall speaking, corporate management level does not have the qualifications of technological innovation audit; it does not conform to the non-independent third party principle.

\section{The workflow}

\section{1 plan technological innovation audit work}

The plan technological innovation audit work's goal is understood that enterprise's present situation, the definition technological innovation audit's goal, distinguishes each kind of disadvantage factor, the formulation technological innovation audit overall strategy and the concrete technological innovation audit plan, confirmed that the technological innovation audit the indicator system, is clear about the technological innovation audit method, the hypothesis audit important level and so on.

\section{2 collect audit's evidence}

The technological innovation audit evidence is to draw the audit conclusion, to form all information which the audit 
opinion uses. We act according to the technological innovation audit objective and the technological innovation audit plan, collection enough suitable technological innovation audit evidence in order to give audit opinion. The data may through the questionnaire survey, the observation, the inquiry, the letter card, test the record; inquire collections related to ERP system.

\section{3 carry on the technological innovation audit sampling}

Along with enterprise size's expansion and information system's consummation, the enterprise has, the complex data massively in the technological innovation process, thus causes to each data to carry on the technological innovation audit becomes is already impossible not to be unnecessary.

Gaining the highly effective accurate evidence and forming the reasonable conclusion needs the technological innovation auditors which accord to the technological innovation audit objective and the related heavy blunder newspaper risk, carry on the technological innovation audit sampling. And then we can analyze the result and give the improvement.

\section{4 form the audit report}

Through to the evidence collection, the reorganization, the analysis, the expert unifies enterprise's goal and the technological innovation market analysis, gives reasonably, the fair and just technological innovation audit conclusion. After the technological innovation report of audit proposes, the expert to the related material risk, the major impact factor and the related department and the personnel will carry on the transportation and the communication, and will supervise to carry out the improve plan. A technological innovation audit work by no means isolated stage, but passes through the process which enterprise technological innovation throughout continues, to revise unceasingly.

\section{Technological innovation audit method}

\section{1 survey forms}

The survey form law is the question which and needs to understand according to the technological innovation audit work's goal, designs the corresponding form, distributes for is solicited by the technological innovation auditors the opinion the method. The survey form law has the technological innovation audit purpose to determine that the tabulation project standard, the essential control point arrange in order the item, easy to judge the choice separately the characteristic. Fills out a form may when the discussion by technological innovation auditors scene filling, may also distribute to the staff fills, special details according to technological innovation audit important level determination.

\section{2 flow chart}

The flow chart is flows through a system's information flow, the viewpoint class or part class graph representative. The flow chart mainly uses for to show some process. This kind of process already may be on production line's technical process, may also completes a duty essential management process. Its merit is (1) based on the system determined that the division of labor (2) marks the division of labor limits control (3) the graphical representation to conform to the engagement standard (4) flow line clear Yi Jian (5) the record to be clear.

\section{3 statistical evaluations}

The statistical evaluation may use in discovering between each data to cancel checks the relations, the latent technological innovation audit risk. Simple statistical evaluation tool like EXCEL and so on may use for to analyze the identical production cycle enterprise technological innovation situation and the competitor fit and unfit quality.

\section{4 analysis procedural laws}

The analysis program is refers to the technological innovation auditors through between the research different data between as well as each different categorical data intrinsic relations, makes the appraisal to the evidence. The analysis program also includes the investigation recognition to have the information inconsistent or with the anticipatory data serious deviation fluctuation reason.

\section{Conclusions}

To the technological innovation implementation audit, needs us to the divergent interest counterparts' request and enterprise's characteristic, conducts the concrete research, must pay attention to the indicator system establishment specially the rationality, this will be a present technological innovation auditing research important topic.

\section{References}

Vittorio,Chiesa,Paul,Coughlan,and Chris,A,Voss.(1996).Development of a Technical Innovation Audit. Journal of 
Product Innovation Managemene, 13,105-136.

Adler, Paul, S, McDonald, D, William and Macdonald,Fred.(1992).Strategic Management of Technical Functions.Sloan Management Review,winter,19-37.

OECD \& EUROSTAT. (1997). Oslo Manual.Paris: OECO Publishing, (Chapter 2).

Elenkov,D. (2002).Effects of leadership on organizational performance in Russian companies.Journal of Business Research.55,467-480.

Powell, W, W, Koput K and Smith-Doerr L Interorganizational collaborations and the locus of innovation: Networks of learning in biotechnology. (1996). Administrative Science. Quarterly, 116-145.

Table 1. The audit shareholder and content and object.

\begin{tabular}{|c|c|c|c|c|c|c|c|}
\hline \multicolumn{2}{|c|}{ content and content $\quad$ shareholder } & innovation funds & supervision & Bank & $\mathrm{VC}$ & owner & manager \\
\hline \multirow{5}{*}{ Basic process } & Technological innovation plan & $\sqrt{ }$ & $\sqrt{ }$ & & $\sqrt{ }$ & & $\sqrt{ }$ \\
\hline & Initiating a project & & & $\sqrt{ }$ & $\sqrt{ }$ & $\sqrt{ }$ & $\sqrt{ }$ \\
\hline & Technological innovation practice & & & & $\sqrt{ }$ & $\sqrt{ }$ & $\sqrt{ }$ \\
\hline & Technological innovation examination & $\sqrt{ }$ & & & $\sqrt{ }$ & & $\sqrt{ }$ \\
\hline & Technological innovation marketability & & $\sqrt{ }$ & & $\sqrt{ }$ & $\sqrt{ }$ & $\sqrt{ }$ \\
\hline \multirow{5}{*}{ Auxiliary system } & Resources supplies & & & $\sqrt{ }$ & $\sqrt{ }$ & $\sqrt{ }$ & $\sqrt{ }$ \\
\hline & Environment & & $\sqrt{ }$ & & & & $\sqrt{ }$ \\
\hline & Surveillance and appraisal & $\sqrt{ }$ & $\sqrt{ }$ & & $\sqrt{ }$ & $\sqrt{ }$ & $\sqrt{ }$ \\
\hline & Coordinated and communication & $\sqrt{ }$ & & & $\sqrt{ }$ & & $\sqrt{ }$ \\
\hline & Control & $\sqrt{ }$ & & & $\sqrt{ }$ & & $\sqrt{ }$ \\
\hline
\end{tabular}

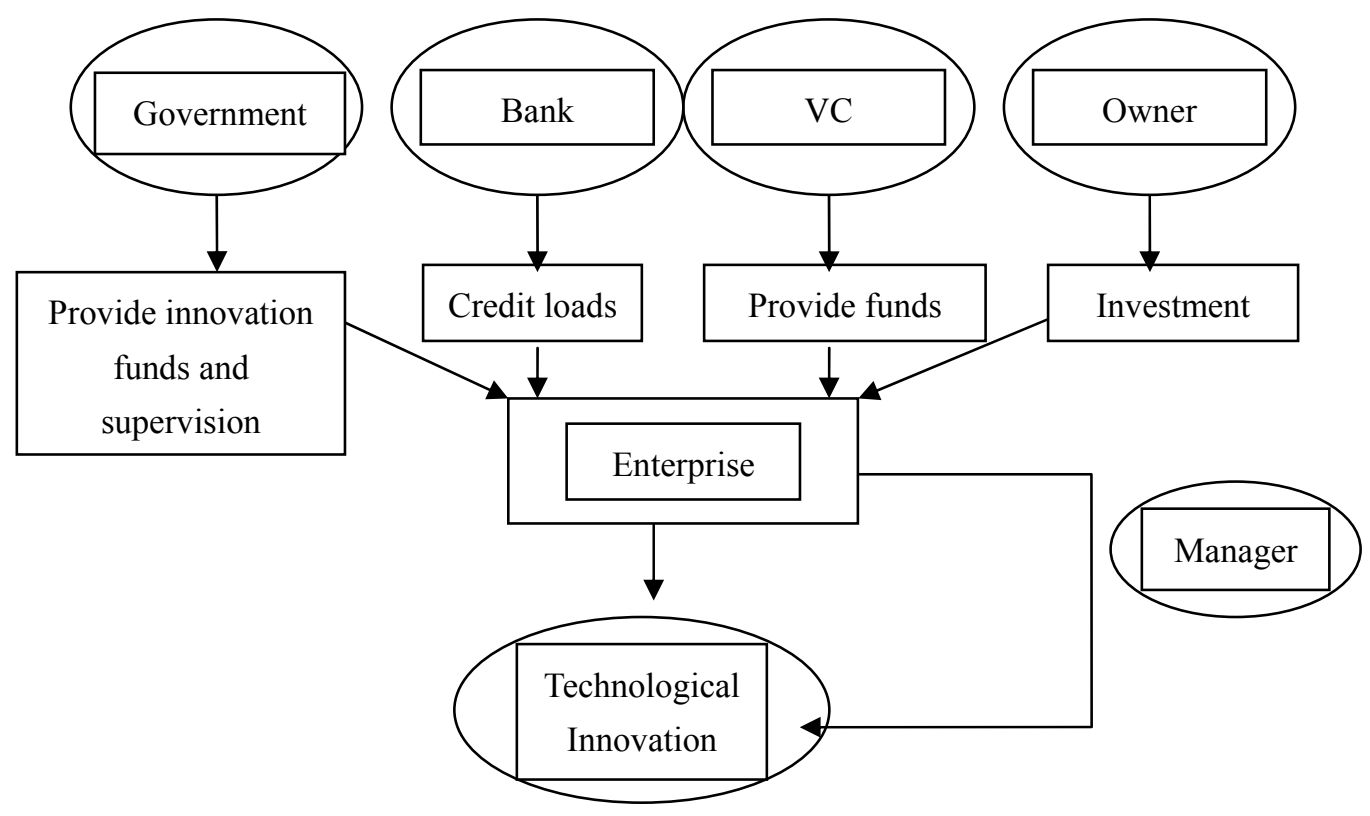

Figure 1. Technological Innovation Stakeholders 


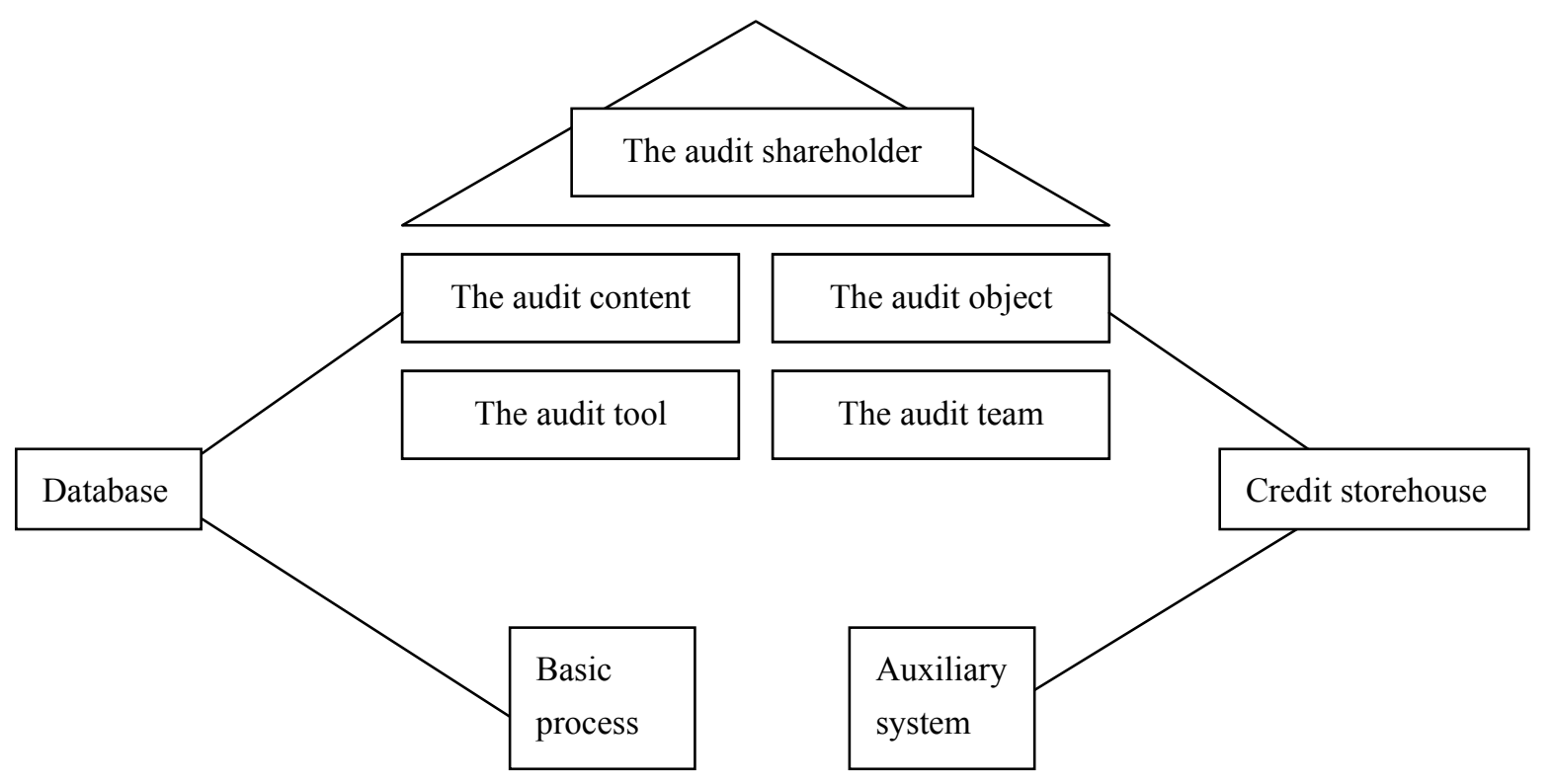

Figure 2. Technological Innovation Audit Model 